\title{
GIS IN ARMY: APPLICATION OF GIS IN GEO-RECONNAISSANCE AND C4IS IN ARMY PURPOSES
}

DOI: http://dx.doi.org/10.18509/GBP.2016.21

UDC: 004:528.85]:355.31(497.7)

\author{
MSc Aleksandar Petrovski, PhD student \\ BSc Mihajlo Toshesvki \\ University "Goce Delchev" Shtip, Military Academy "General Mihailo Apostolski" associated \\ member, Skopje, Macedonia
}

\begin{abstract}
Information in $21^{\text {st }}$ century represents power, and with that, safest and most legitimate "machine for dominating". Consequences from the rapid growth of information technologies and their usage for army purposes make information one of the key concepts of the unconventional warfare. Application of GIS (Geographical Information System) in the Army for getting information is wide used all over the world, but this paper gives an overview and make particular ideas for further development in usage of GIS for georeconnaissance and C4IS. The main aim is getting specific information about objects, buildings and devices on the battlefield through geo-location and plots field data (various digital, video images), further management and planning strategies for ensuring proper security, and also in other way, getting information from the intelligence services for attacking and planning routes of movement, all that based on the information from the GIS. In this paper, despite the overview of GIS usage for geo-reconnaissance in army, is presented an application for the soldiers on the battlefield for live streaming (drones and video camera) and live processing of the decisions from their commands, getting real time track log with moving map (through a GPS signal), which displays their current coordinate location, and their heading directions given by their commanders. The development of this kind of application based on GIS, will make a breakthrough in military reconnaissance, helping in the military decision making process.
\end{abstract}

Keywords: GIS, army, geo-reconnaissance, decision, battlefield.

\section{INTRODUCTION}

Armies in the 21st century have to manage with difficult operations in the field of unconventional warfare. Today, battles are won in the middle of the big cities and on the computers in the operational center where the information is the most powerful tool. Buildings and streets are the new battlefield, in which every corner hides different type of danger. Soldiers have very difficult task, to observe and save themselves from the various attacks.

To eliminate these dangers and transform them in favorable role, armies must change "old" topographic maps with new modern maps in which the main point won't be on how steep is the ground, or is the following dense vegetation passable or not. These elements are also important, but they are easy readable from the "old" maps. New modern maps should allow to the armies in the world to be one step ahead of the enemy. They should enable to the command unit to know exactly what lays behind the object, after the hill, or in the deepest parts of the hole. The term "modern" map, covers, of course, not only the 
up-to-datedness, transparency (that is, being able to be used simply, from the user's point of view) and increasing precision, but also a higher-than- average information content that supports military use to the greatest extent possible, considering special military aspects. [1]

This is what GIS is about: to display special kind of information about specific area with unlimited amount of essential mapping information (layers), used to display the knowledge base of that area.

\section{GIS IN GEO- RECONNAISSANCE}

GIS is widely used in almost all the branches of the modern armies. Capabilities that use GIS are following: Command and Control, Defense mapping organizations, Base operations and facility management, Force protection and security, Military engineering, Mine clearance and mapping, Mission planning, Terrain analysis etc. [2]

The term reconnaissance means preliminary observation or research of a specific field for a mission to obtain information about the enemy or to locate it. Geo-reconnaissance determine specific type of information gathered from the visual observation or other detection methods, which give us information's about the terrain, geographical elements of it, objects on that specific area, that can help us to create a better picture for the enemy and the resources they are using.

So, one of the ways of data gathering is by aerial photographs and space images. Advantage of these kind of collecting data is the possibility of gaining information without getting any contact with the earth surface directly, but with contacting a mediatory unit carrying information about the surface. As that kind of mediatory unit which carry an assessing equipment to gain information are today's popular unmanned aerial vehicle (UAC) commonly known as a drone. With a proper equipment they can be used to observe and make a live photographs of the enemy terrain. This method will reduce the usage of people risking their life for the purpose of collecting information.

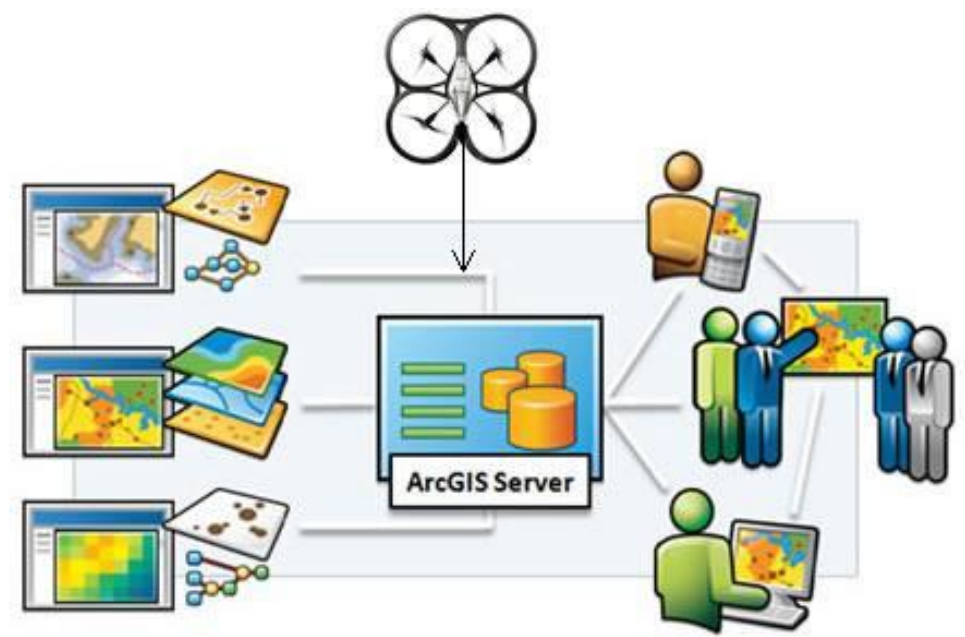

Figure 1. GIS Cloud mapping with UAV

From this point, knowing the terrain and selecting the required layers, commanding unit can create attacking and planning routes of movement. Also based on the information from the GIS, analyzing the area of defense, they can place mines, fortification objects, and other obstacles for better assertion and defending the proper area. 
Using Arc-GIS Military Analyst, which maximize the use of standard suite of defense data products by directly reading and rendering vector and raster products, line-of-sight assessments, Military Grid Reference System (MGRS) conversion, and Digital Terrain Elevation Data (DTED) analysis [2]. Using the coordinate tool, which supports MGRS and coordinate conversion, commanders of artillery units can use it for fast and specific directing and elevating of their artillery weapons, supporting the front rows of the infantry.

But despite all that information from the GIS and the decisions made by the commanding unit, work is done on the battlefield. So all the information's are vain, if there is no one to transfer the commands into a real action. Soldiers are the ones who do that. The application tracks the movement of the soldiers and sent to the controlling unit. This enables to check the progress of the mission. Also from the command unit, a planned route is sent to every soldier particularly, which give the possibility to manage with the mission even before it is started on the battlefield. Along the heading coordinate readout and the current coordinates are written in the memory.[3]

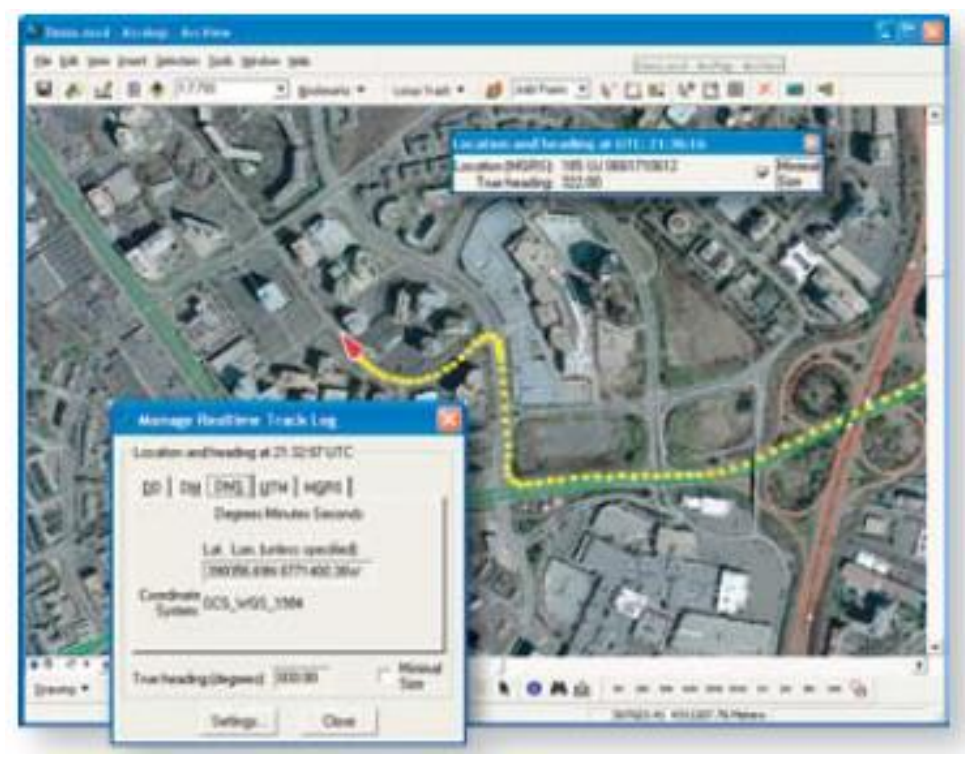

Figure 2. Locus track log

Geo-Rover also allows to download track logs and waypoints from GIS receivers into new or existing GIS data layers. This enable to analyze the movement and refer to the mistakes made during the mission.

Other important feature is the Military Overlay Editor (MOLE) consisted in Arc-GIS Military Analyst which supports MIL-STD 2525B and custom war-fighting symbols. With this feature, commanders can: add geographical data in vector, raster, or other supported formats for reference while composing and positioning unit symbols; Manually or automatically add leader lines to multiple symbols that occur at the same location; Stack symbols of identical units that occur at the same location; Print draft copies of your map to any standard Windows output device; Use graphics generated by MOLE in Windows-based Arc-GIS.

At the end, MOLE will definitely help the commanding units of making and sharing the tactical presentation of their vision. 


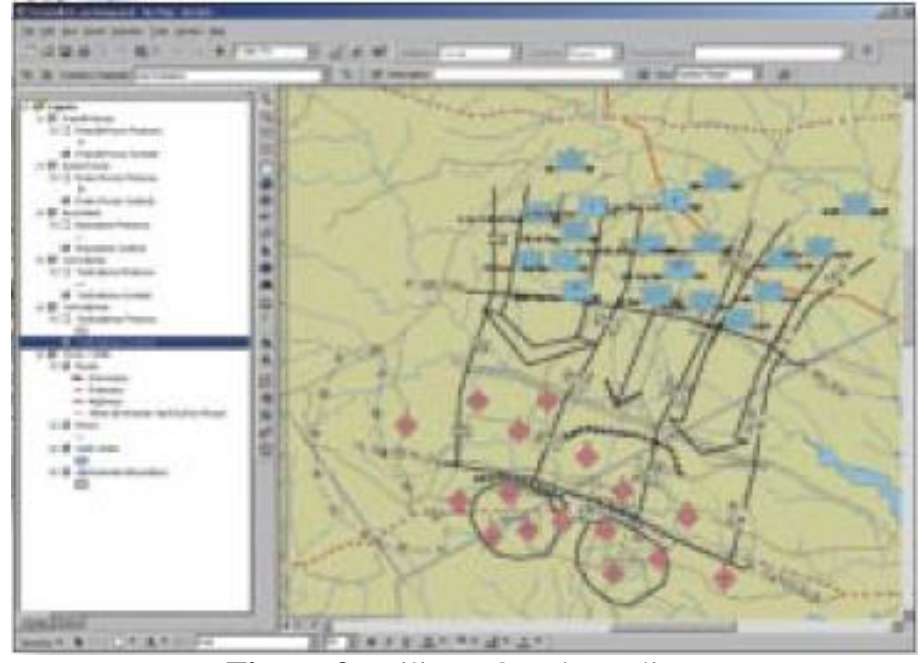

Figure 3. Military Overlay Editor

\section{GIS IN C4IS}

C4IS defines a Command, Control, Communication, Computer and Information system. The Arc-GIS platform is an enterprise information technology infrastructure, and as such, provides a horizontal, crosscutting technology that is very different from GIS technologies past niche usage [4]. One concept made a big step up in the usage of GIS for military purposes, especially military affairs. That is NCO which represents concept of Network-Centric Operations i.e. the use of the network to connect decision making across multiple defense domains and beyond. Therefore, NCO is about far more then war fighting. It connects war fighting to strategic intelligence, and with that to installation management. This frame is way beyond from the traditional defense and intelligence domain. Arc-GIS has a critical impact in each of the three concepts of NCO:

- $\quad$ Intelligence, Surveillance, Reconnaissance - ISR;

- $\quad$ Command, control, communications, computers, and intelligence - C4I;

- $\quad$ Precision engagement - PE

The C4I domain supports timelier and better decisions by using a variety of tools to analyze, assess, and plan actions. Arc-GIS bolsters C4I capabilities by providing a common spatial context and the tools to provide decision makers, commanders, and war fighters with a distributed, scalable, decision support environment.

The development of military commanding and management technique systems seen in recent years has been made possible primarily by the development of microelectronics, the rapid decrease in size of IT tools, the enormous increase of their capacity, and the integration of their capabilities into a single system. This is applied by maneuvering robot aircrafts, unmanned flying devices and by all other armament managing, deployment managing systems, which are, on the one hand in an interactive contact with the environment, and direct interactively the given object, on the other [4]. Nowadays all elements of managing systems are integrated into a combat vehicle, which forward commands to the managing staff of the vehicle and send back reports. Based on reports, a close to real-time combat value can be worked out, which in the case of traditional tools would be slow, cumbersome procedure full of uncertainties, requiring human resource.

In the US military, the Commercial Joint Mapping Toolkit (C/JMTK) provides the Mapping, Charting, Geodesy, and Imagery (MCG\&I) functionality for C4ISR mission applications. The toolkit is being deployed to support both legacy mission applications 
and new systems being developed throughout the Department of Defense (DoD) Command, Control, and Intelligence (C2I) Community. [5]

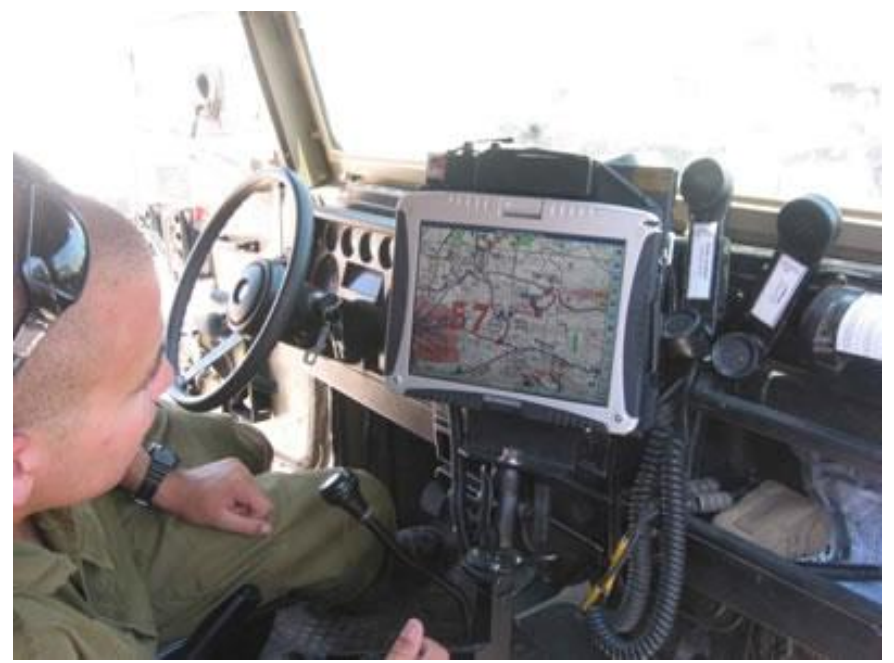

Figure 4: Integrated Communications C4I Systems For Security Applications

Advanced wireless communications integrated with command, control and computer systems are combined with the IDF new Tactical Operational Command and Control Headquarters system (TORC2H) deployed by the for border security was integrated by Elbit Systems, unifying sensors, security forces and command centers into the regional security $\mathrm{C} 2$ system. It is sharing situational picture and rapidly transferring reports and decisions between commanders in Command Post and in the field, to and from forward elements. between sensors and field units. Geographical Information Systems (GIS) displayed relevant data with geographical features, over 3D or 2D digital maps. It also supports virtual presentation of the target and situation, as viewed by each of the different forces. TORC2H uses vehicular mounted as well as dismounted, units, facilitating continuous monitoring of situations via sensors images, visualization of unit deployment, location and status, rapid and transparent messaging of command, reports and situational reports, etc. The system was selected by the IDF for border protection command and control and is deployed along the lines separating the Israeli and Palestinian authority controlled area. [6]

\section{INFORMATION SYSTEM - GEO-RECONNAISSANCE AND COMMANDING}

Composing two previous GIS concepts into one model of information system is the main idea of this paper. Creating an appropriate application for portable devices based on the model of the information system will ease the usage of these complex concepts. The Georeconnaissance and commanding (GRC) information system is based on the GIS usage for both Geo-reconnaissance and C4IR - Command, Control, Communication, Computer, Information and Reconnaissance. So through the wide utilization of GIS we want to create one completely defined information system which will help soldiers, commanders and strategic decision makers, for easily observation of their current situation, their future actions and of course after the end of the mission, feedback and analyzing of the mistakes and creating directions for further improvement.

$1^{\text {st }}$ step into creating of this kind of complex system is equipping the direct participants i.e. soldiers with proper equipment for geo locating, and that will be an emitter which will 
constantly send signals. The receiving device, because sometimes the terrain is not accessible for all kinds of vehicles, will be set on the drone and it will forward the signals to commander. The device set on this drone also will be in a role as an emitter, so it will sent various kind of signals to the soldiers on the battlefield.

$2^{\text {nd }}$ step is receiving the information about the location of the unit and the soldiers in the commanding unit. In this unit, the commander with the help of the staff (headquarters) based on the locations of the soldiers shown on the monitor using GIS software (Arc-GIS and Geo-Rover), decides what actions will be taken. In this section, biggest impact on the functioning of the information system has GIS usage for C4IS, described already in the previous topic. Arc-GIS capabilities help in the decision making process, giving to commanding unit various kind of information, from situational picture on the field, to decisions made by other commanders, visualization of unit deployment, reports, and of course information received from the geo-reconnaissance.

Geo-reconnaissance actually is the parallel step to the geo-location step. Georeconnaissance, in fact is the major element of this information system. With aerial photography, infrared sensors, space images, the command gets data and information about the situation on the enemy territory, about the enemy's soldiers, objects in the deep of the enemy line, fortification obstacles, and other information that can be beneficial later in the decision making process.

Geo-locating and Geo-reconnaissance give the input values in the information system. Than human factor, make a decision, which represent an output from the system. This output can be in a form: directions about the movement, usage of weapons, withdrawal, locations of IED's. The orders are transferred to lower instances, and at the end every soldier has a specific task to finish. If the "output" represents specific directions about the movement, that order via GPS is shown on the GPS navigator which is a part of the equipment of every soldier.

As an integrated part of the information system is the recording and live streaming section. A camera is set on the drone above the battlefield, so it records the real action. The video is transferred to the command, which can help to make a better decision, if the information received from other sources (geo-reconnaissance, geo-location, radio devices). Also the video material can be used later for analyzing the mission or the battle. Drones are controlled from the command, and their location and movement depends on the requirements of the mission. 


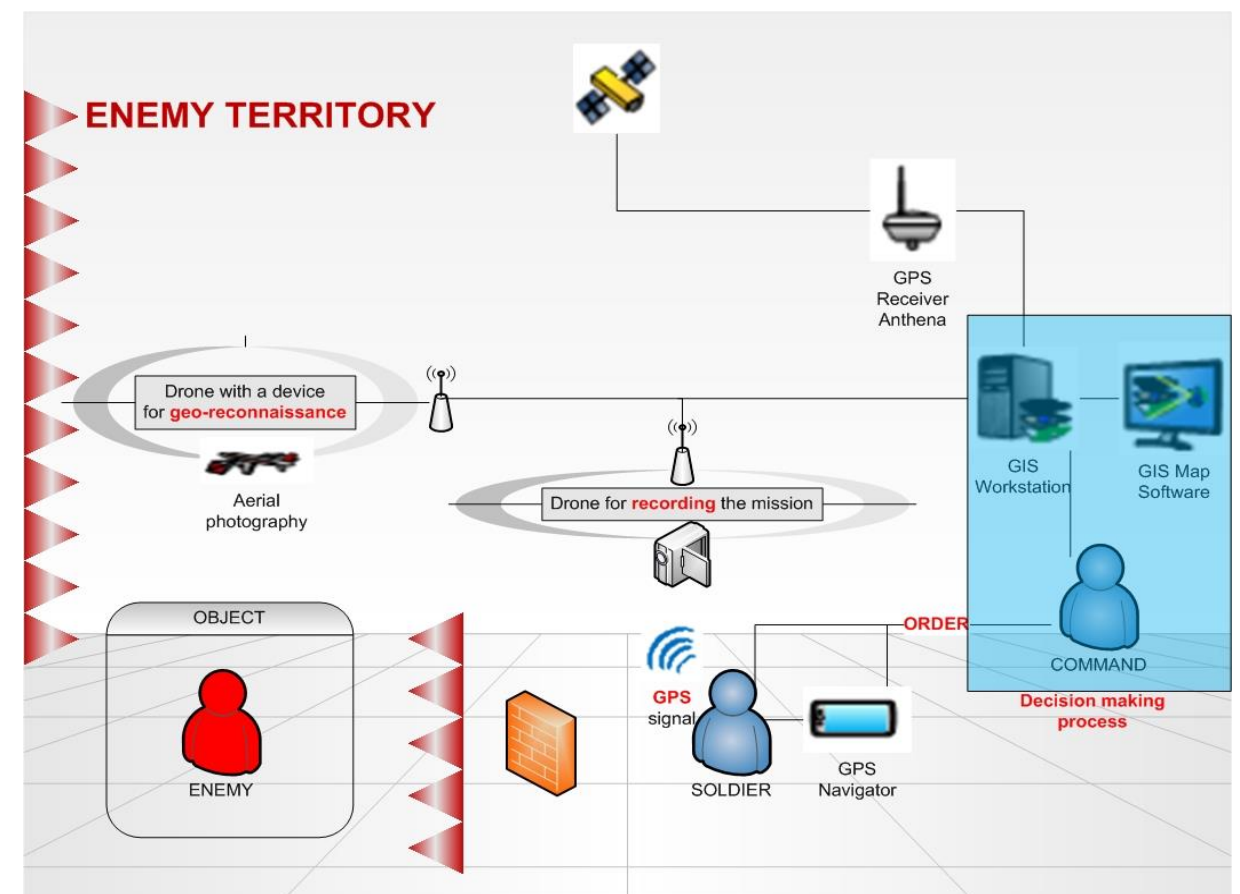

Figure 5. Model of Geo-reconnaissance and commanding (GRC) information system

\section{CONCLUSION}

GIS has a fast growth in today world, but his capabilities are not explored completely. The possibilities that are offered from GIS have a wide range of use, and because of it, this information system nowadays is more and more used in various fields of study. Of course that military industry discovers different ways of composing this information system in manufacturing of new devices, vehicles and weapons and also in integrating of the GIS in the existing technologies.

Some of the usage of GIS is for geo-reconnaissance and C4IS which was previously described in this paper. These subjects are already explored and have application in armies around the world for: tracking units or soldiers, reconnaissance of the enemy's terrain, adding war-fighting symbols and tactical editing of the data from the battlefield, rapid and massive transferring of messages and orders, coordinate conversion, digital terrain elevation data information etc.

A military information system based on connecting of these two powerful usages of GIS, will help the armies in the world and the decision makers for better observation on the mission or battle and giving specific orders based on the information's collected from geo-reconnaissance and live-streaming of the situation on the battlefield. Input values for the commanders represent the data from the geo-reconnaissance i.e. the situation on the enemy's terrain and the geo-location of the own units and soldiers. The command make a decision which represents an output value of the system, and it is send to the soldiers as a voice order or as movement navigation.

\section{REFERENCES}

[1] Peter Nagy, "GIS in the army of 21st century", Hungary, 2004, pp587-600;

[2] ESRI, "GIS for Defense and Intelligence", 2005.

[3] ESRI, "GeoRover Tools for ArcGIS", 2006 
[4] L. VÁNYA: "Military GIS and Their Application During Training and Education." Presentation material, Budapest ZMNE, 2000

[5] Stanzione, Thomas, and Kevin Johnson. "GIS enabled modeling and simulation (GEMS)". MAK TECHNOLOGIES INC CAMBRIDGE MA, 2007.

[6] http://defense-update.com/events/2005/summary/LIC-c4sec.htm 